\title{
PERBANDINGAN PRESTASI BELAJAR SISWA YANG MENGIKUTI BIMBINGAN BELAJAR DAN TIDAK MENGIKUTI BIMBINGAN BELAJAR SISWA KELAS V SDN 01 TULUS AYU
}

\author{
Prima Septiana Anggraeni, Sri Enggar Kencana Dewi \\ STKIP Nurul Huda Sukaraja Oku Timur \\ E-mail: enggar@stkipnurulhuda.ac.id
}

\begin{abstract}
Abstrak
Penelitian in bertujuan untuk mengetahui prestasi belajar pada siswa yang mengikuti bimbingan belajar dan tidak mengikuti bimbingan belajar siswa kelas V di SDN 01 Tulus Ayu serta untuk mengetahui perbedaan apa saja yang terdapat pada siswa yang mengikutI bimbingan belajar dan tidak mengikuti bimbingan belajar. Dalam penelitian ini peneliti menggunakan metode penelitian kuantitatif. Instrumen penelitian yang digunakan dalam penelitian ini adalah observasi dan dokumentasi. Data yang terkumpul diolah dengan analisis statistic deskriptif dan analisis statistic inferensial(Independent sample $t$ test. Hasil analisis deskriptif hasil belajar siswa yang mengikuti bimbingan belajar masuk dalam kategori tinggi karena melebihi standar KKM disekolah yaitu dengan mean 83.09 dan siswa yang tidak mengikuti bimbingan belajar 76.32 . Berdasarkan data yang diperoleh dapat diketahui bahwa bimbingan belajar berpengaruh signifikan terhadap hasil prestasi belajar siswa. Dari hasil analisis inferensial menunjukan $\mathrm{T}_{\text {hitung }} 11.364$,sedangkan $\mathrm{T}_{\text {tabel }} 2.018$ penelitian ini menggunakan taraf signifikan 0.05 . Dengan demekian $\mathrm{T}$ hitung jauh lebih besar $\mathrm{t}$ tabel, dan hipotesis nihil ditolak,artinya terdapat perbedaan prestasi belajar siswa yang mengikuti bimbingan belajar dan tidak mengikuti bimbingan belajar siswa kelas V SDN 01 Tulus Ayu.
\end{abstract}

Kata kunci: Bimbingan Belajar, Prestasi belajar

\section{PENDAHULUAN}

Pendidikan merupakan sesuatu yang memiliki tujuan yang sangat penting untuk diperoleh. Dalam skala nasioanal,tujuan dalam pendidikan adalah untuk mengembangkan kemampuan dan kompetensi yang ada pada anak.Terkait dengan dunia pendidikan maka, tidak akan terlepas dari yang namanya proses belajar. Karena belajar merupakan aktifitas penting yang dilakukan oleh siswa secara terus menerus agar memperoleh suatu perubahan baik dari ranah kognitif, afektif, maupun psikomotoriknya(Syaiful Bahri.2008:13).

Usaha untuk meningkatkan prestasi belajar dalam segala bidang sering dilakukan. Pemberian motivasi dari orang tua atau wali murid, teman, serta tenaga pendidik sehingga dapat memberikan arti bagi individu dalam meraih prestasi belajar secara optimal. Salah satunya untuk meningkatkan prestasi belajar anak di sekolah yaitu perlu mengulang-ulang pelajaran di luar sekolah.Sayangnya banyak orang tua anak yang kesulitan dalam mendampingi anaknya dikarenakan kesibukan sebagai orang tua,atau pelajaran anak belum diapahami oleh orang tua,belum lagi PR yang diberikan oleh guru yang lainnya membuat anak sulit memecahkan masalah nya sendiri sehingga anak malas untuk menyelesaikan masalahnya

Dengan demikian,untuk mengatasi masalah tersebut lebih baik diberikaan layanan bimbingnabelajar agar mereka efektif dan efesien dalam belajar dan dapat memperoleh prestasi belajar yang baik dan membanggakan. Saat ini banyak sekali bimbingan belajar yang ada diberbagai tempat dari bimbingan belajar yang berbentuk lembaga bimbingan belajar atau les privat yang diadakan dirumah-rumah warga. Melalui pelayanan bimbingan belajar tersebut diharapkan dapat membantu perkembangan anak didik. Pemberian bimbingan belajar itu sendiri bertujuan untuk membantu anak-anak yang mengalami masalah di dalam memasuki proses belajar dan situasi belajar yang diharapkan anak termotivasi dalam mencapai prestasi yang memuaskan dan mampu menerapkan ilmu pengetahuan yang didapat dari sekolah.

Bimbingan belajar adalah suatu proses pemberian bantuan dari guru/guru pembimbing kepada siswa dengan cara mengembangkan suasana belajr yag kondusif dan menumbuhkan kemamampuan agar siswa terhindar dari dan atau dapat mengatasi masalah atau kesulitan belajar yang mungkin dihadapi nya sehainggga mencapai hasil 
belajar yang optimal.Kelebihan dari Bimbingan belajar adalah diantara sebagai berikut,(1) Memiliki pengalaman dari sekolah lain,(2)Membuat Anak memanfaatkan waktu luang dengan baik,(3)Membuat anak belajar terus menerus,(4)Membantu abak memahami materi disekolah.

Penelitian tentang perbandingan prestasi belajar siswa yang mengikuti bimbingan belajar dan siswa yang tidak mengikuti bimbingan belajar ini pernah diteliti oleh Afriha Yuliati, menurutnya prestasi belajar siswa yang mengikuti bimbingan belajar lebih baik dari pada prestasi belajar siswa yang tidak mengikuti bimbingan belajar

Alasan mengambil judul penelitiain adalah karena saya tertarik dengan masalah yang ada disekolah salah satunya yaitu perbedaan yang terdapat pada beberapa siswa yang mengikuti bimbingan belajar dan saya ingin melihat perbedaan yang ditimbulkan pada siswa yang mengikuti dan tidakmengikuti selain itu juga membandingkan hasil belajar bagi siswa yang mengikuti dan tidak mengikuti bimbingan belajar pada siswa kelas V di SDN 01 Tulus Ayu.Sehingga peneliti dapat merumuskan permasalahan diatas dalam judul penelitian "Perbandingan Prestasi belajar siswa yang mengikuti bimbingan belajar dan tidak mengikuti bimbingan belajar di kelas V SDN 01 Tulus Ayu"

Berdasarkan judul danlatar belakang masalah maka masalah penelitian nya dapat dirumuskan sebagai berikut (1).Seberapa besar prestasi belajar siswa yang mengikuti bimbingan belajar dan prestasi belajar siswa yang tidak mengikuti bimbingan belajar kelas V di SDN 01 Tulus Ayu? . (2). Adakah terdapat perbedaan antara prestasi belajar siswa yang mengikuti bimbingan belajar dan tidak mengikuti bimbingan belajar siswa kelas V di SDN 01 Tulus ayu?

\section{METODE/EKSPERIMEN}

Metode yang digunakan dalam penelitian ini adalah penelitian kuantitatif yang bersifat perbandingan/komparatif dengan metode studi kasus. Desain penelitian adalah rencana atau rancangan yang dibuat oleh peneliti,sebagai ancer-ancer kegiatan yang akan dilaksanakan(Arikunto,2006:44). Sampel yang di ambil menggunakan teknik tidak acak (non random). Dalam penelitian ini yang menjadi instrument penelitian adalah nilai raport siswa kelas IV Semester 2 yang dinyatakan dalam bentuk angka yang diperoleh dari proses belajar mengajar selama satu semester. Adapun analisis data untuk penelitian ini menggunakan analisis statistik deskriptif dan analisis statistik inferensial

\section{HASIL DAN PEMBAHASAN}

Hasil

Adapun analisis data untuk penelitian ini menggunakan analisis statistik deskriptif dan analisis statistik inferensial.Sedangkan analisis statistik inferensial digunakan untuk menjawab pertanyaan penelitian mengenai apakah ada perbandingan prestasi belajar antara siswa yang mengikuti bimbingan belajar dan tidak mengikuti bimbingan belajar.Adapun analisis statistik inferensial untuk penelitian ini mengunakan ujit (Independent sample t-test).Adapun syarat yang harus dipenuhi sebelum uji t tersebut adalah uji normalitas dan homogenitas varians.

Adapun hipotesis statistik dalam pengujian ini dirumuskan sebagai berikut: Ho : Sebaran data sampel yang diperoleh dari populasi berdistribusi normal. Ha : Sebaran data sampel yang diperoleh dari populasi berdistribusi tidak normal.

a.Hasil Prestasi belajar siswa yang mengikuti bimbingan belajar

Tabel 1.Deskripsi data prestasi belajar siswa yang mengikuti bimbel Descriptive Statistics

\begin{tabular}{|l|r|r|r|r|r|}
\hline & $\mathrm{N}$ & Minimum & Maximum & Mean & Std. Deviation \\
\hline Bimbel & 22 & 80 & 87 & 83.09 & 2.136 \\
Valid N (listwise) & 22 & & & & \\
\hline
\end{tabular}

Pada tabel diatas nilai rata rata prestasi siswa yang mengikuti bimbingan belajar adalah 83.09, nilai maksimum yang diperoleh siswa 87 dan nilai minimal yang diperoleh siswa 80 dengan standar deviasi 2.136।

b.Prestasi belajar siswa yang tidak mengikuti bimbingan belajar 
Tabel 2.Deskripsi data prestasi belajar siswa yang tidak mengikuti bimbel Descriptive Statistics

\begin{tabular}{|l|r|r|r|r|r|}
\hline & $\mathrm{N}$ & Minimum & Maximum & Mean & Std. Deviation \\
\hline Tidakbimbel & 22 & 72 & 79 & 76.32 & 1.756 \\
Valid N (listwise) & 22 & & & & \\
\hline
\end{tabular}

Pada tabel diatas nilai rata rata prestasi siswa yang tidak mengikuti bimbingan belajar adalah 76.32, nilai maksimum yang diperoleh siswa 79 dan nilai minimal yang diperoleh siswa 72 dengan standar deviasi 1.756

\section{c.Uji Normalitas}

Uji normalitas yang dimaksud adalah uji normalitas data prestasi belajar siswa yang megikuti bimbingan beljara dengan siswa yang tidak mengikuti bimbingan belajar.Adapun hipotesis statistic dalam pengujian ini diumuskan sebagai berikut,(Ho): Sebaran data sampel yang diperoleh dari populasi berdistribusi normal,(Ha): Sebaran data sampel yang diperoleh dari populasi berdistribusi tidak normal

\section{Tabel 3 uji normalitas Tests of Normality}

\begin{tabular}{lcccrrr}
\hline & \multicolumn{2}{c}{ Kolmogorov-Smirnov $^{\mathrm{a}}$} & \multicolumn{3}{c}{ Shapiro-Wilk } \\
\hline Statistic & Df & Sig. & Statistic & df & Sig. \\
\hline Bimbel & .151 & 22 & $.200^{*}$ & .945 & 22 & .250 \\
Tidakbimbel & .199 & 22 & .023 & .938 & 22 & .178 \\
\hline
\end{tabular}

\footnotetext{
a. Lilliefors Significance Correction

*. This is a lower bound of the true significance.
}

Berdasarkan hasil olah data pada program SPSS untuk pengujian normalitas prestasi belajar siswa yang yang mengikuti bimbingan belajar dan tidak mengikuti bimbingan belajar,baik secara Shapiro Wilk atau uji Liliefors(Kolmogrov-Sornov) diperoleh masing-masing 0.200 dan 0.250 dan prestasi belajar siswa yang tidak mengikuti bimbingan belajar memperoleh masing-masing 0.200 dan 0.178 . Nilai signifikan semua data lebih besar 0.05.Jadi keputusan yang diambil terima Ho yang berarti bahwa data berdistribusi normal.

\section{d. Uji Homogenitas}

Pengujian Homogenitas yang penulis lakukan dalam penelitian ini dengan menggunakan bantuan program SPSS.Uji homogenitas yang dimaksud adalah uji homogenitas data prestasi belajar siswa kelas V antara siswa yang mengikuti bimbingan belajar dan tidak mengikuti bimbingan belajar.

Tabel 4 Uji homogenitas prestasi siswa yang mengikuti bimbel Test of Homogeneity of Variances

Bimbel

\begin{tabular}{rrrr}
\hline Levene Statistic & df1 & df2 & Sig. \\
\hline .578 & 5 & 15 & .716 \\
\hline
\end{tabular}

Berdasarkan hasil olah data pada program SPSS untuk pengujian homogenitas prestasi belajr siswa yang mengikuti bimbingan belajar dengan uji Levene Statistic diperoleh nilai signifikansi 0.716 lebih besar 0.05.Karena signifikansi lebih besar dari 0.05 maka dapat disimpulkan bahwa data prestasi siswa yang mengikuti bimbingan belajar dengan siswa yang tidak mengikuti bimbel berasal dari varians yang sama 
Tabel 5 Uji homogenitas prestasi siswa yang tdk mengikuti bimbel

Test of Homogeneity of Variances

Tidak Bimbel

\begin{tabular}{rrrr}
\hline Levene Statistic & df1 & df2 & Sig. \\
\hline 2.298 & 5 & 14 & .101 \\
\hline
\end{tabular}

Berdasarkan hasil olah data pada program SPSS untuk pengujian homogenitas prestasi belajr siswa dengan uji Levene Statistic diperoleh nilai signifikansi 0.101 lebih besar 0.05.Karena signifikansi lebih besar dari 0.05 maka dapat disimpulkan bahwa data prestasi siswa yang tidak mengikuti bimbingan belajar dengan siswa yang mengikuti bimbingan belajar memiliki varians yang sama.

\section{d. Uji Independent sample t test}

Sebelum dilakukan uji $\mathrm{t}$ test (Independent Sample $t$ Test) sebelum nya dilakukan uji kesamaan varian(homogenitas) dengan $\mathrm{F}$ test(Levene,s test) artinya jika varians sama maka uji $\mathrm{t}$ menggunakan Equal Variance Assumed(Diasumsikan varians sama) dan jika varians berbeda maka menggunakan equal not variance assumed(diasumsikan varian berbeda)

Tebal 6

Group Statistics

\begin{tabular}{lccrrr}
\hline \multirow{2}{*}{ Prestasi } & kelompok & N & Mean & Std. Deviation & Std. Error Mean \\
& bimbel & 22 & 83.09 & 2.136 & .455 \\
& tidak bimbel & 22 & 76.55 & 1.654 & .353 \\
\hline
\end{tabular}

Dari tabel diatas dapat terlihat untuk nilai rata-rata(mean) siswa yang mengikuti bimbingan belajar yaitu diperoleh nilai sebesar 83.09 ,Std.Deviation 2.136 dan std error mean 0.455. Untuk nilai rata-rata(mean) siswa yang tidak mengikuti bimbingan belajar yaitu diperoleh nilai sebesar 76.55 ,Std.Deviation 1.654 dan std error mean 0.353

Tabel 7

Independent Samples Test

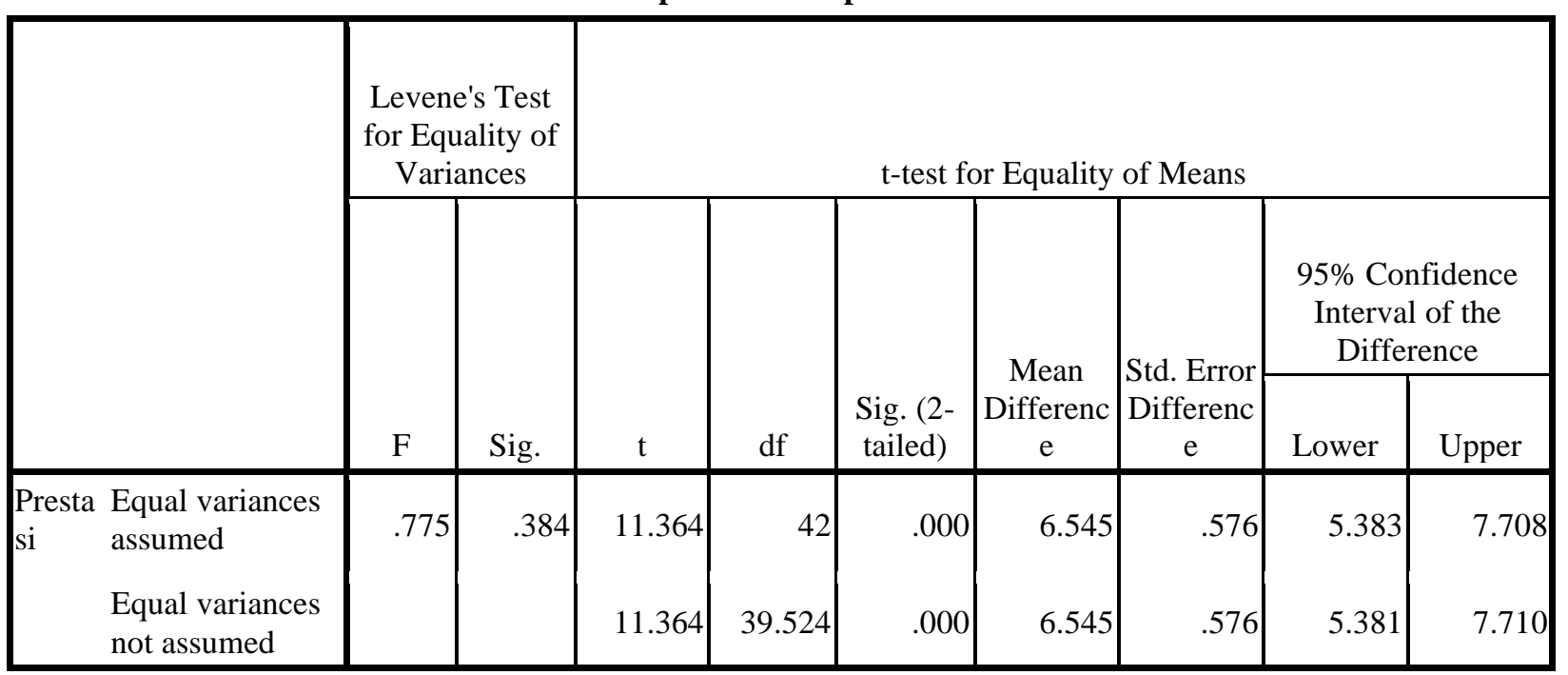

\section{PEMBAHASAN}

Berdasarkan hasil penelitian yang telah dilakukan hasil observasi yang menunjukan bahwa siswa yang 
mengikuti bimbingan belajar rata-rata dalam kegitan proses pembelajaran nya sudah Baik.Sedangkan untuk siswa yang tidak mengikuti bimbingan belajar rata-rata kurang baik.Artinya dalam proses pembelajaran pun siswa yang mengikuti bimbingan belajar lebih menonjol dalam proses pembelajaran dikelas dibandindingkan dengan siswa yang tidak mengikuti bimbingan belajar.

Sedangkan hasil prestasi belajar siswa yang diolah melalui spssdidapatkan hasil bahwa nilai $\mathrm{t}$ tabel $>\mathrm{t}$ hitung $(6.855>2.048)$ dan signifikansi $(0.000<0.50)$ makA Ho ditolak.Artinya bahwa ada perbandingan antara siswa yang mengikuti bimbingan belajar dan tidak mengikuti bimbingan belajar. Ini dibenarkan dengan tabel Group Statistics terlihat rata-rata (Mean) untuk siswa yang mengikuti bimbingan belajar 82,73 dan siswa yang tidak mengikuti bimbingan belajar 76,80 artinya bahwa rata-rata nilai siswa yang mengikuti bimbingan belajar lebih tinggi daripada siswa yang tidak mengikuti bimbingan belajar.

Menurut Abu Ahmadi dan widodo Supriyono (2004: 111) tujuan pelayanan bimbingan belajar secara umum adalah membantu murid-murid agar mendapatkan penyesuaian yang baik didalam situasi belajar,sehingga setiap murid dapat belajar dengan efesien sesuai kemampuan yang dimilikinya,mencapai perkembangan optimal.

Hal ini selaras dengan hasil belajar serta hasil observasi yang dilakukan oleh peneliti bahwa denga mengikuti bimbinga belajar artinya siswa dapat belajar lebih efeien karnea mendapatkan bimbingan dalam memahami materi disekolahan dengan waktu terbatas dengan kemampuan nya sendiri dengan bantuan orang lain atau guru bimbel. Sehingga siswa dapat berkembang sesuai usia dan tingkatan nya dengan optimal.

Dengan demekian,berdasarkan penelitian ini dapat dikatakan bahwa perbandingan prestasi belajar siswa yang mengikuti bimbingan belajar lebih tinggi dibandingkan siswa yang tidak mengikuti bimbingan belajar

\section{PENUTUP}

Berdasarkan hasi pembahasan dan hasil deskripsi data pada bab IV maka dapat diambil kesimpulan sebagai berikut:

1. Prestasi belajar siswa yang mengikuti bimbingan belajar kelas V SDN 01 Tulus Ayu diperoleh rata-rata sebesar 83.09 dengan nilai siswa yang diperoleh siswa 87 dan minimum yang diperoleh 80. Rata-rata nilai siswa yang mengikuti bimbel dikategorikan tinggi karena melebihi standar KKM yang ditetapkan disekolah

2. Rata-rata nilai yang tidak mengikuti bimbingan belajar adalah 76.32 ,nilai maksimum yang diperoleh siswa 79 dan nilai minimum yang diperoleh siswa sebsar 72. Rata-rata nilai siswa yang mengikuti bimbel dikategorikan tinggi karena melebihi standar KKM yang ditetapkan disekolah

3. Berdasarkan hasil uji hipotesis prestasi belajar antara siswa yang mengikuti bimbingan belajar dengan siswa yang mengikuti bimbingan belajar didapatkan nilai sig (2-tailed) $=0.000$ dan nilai $\mathrm{t}_{\text {hitung }}>\mathrm{t}_{\text {tabel }}$ $(11.364>2.018)$. Oleh karena itu keduanya didapatkan dari alfa yang ditetapkan $(\alpha=0.05)$ dan nilai $\mathrm{t}$ hitung > t tabel, maka keputusan yang diambil adalah ditolak $\mathrm{H}_{\mathrm{o}}$, Yang berarti bahwa prestasi belajar siswa yang mengikuti bimbingan belajar lebih tinggi dengan siswa yang tidak mengikuti bimbingan belajar.Sehingga terdapat perbandingan yang muncul.

\section{UCAPAN TERIMAKASIH}

1. Kedua orang tuaku, Bapak Jupri Alamsyah dan Ibu Alviana, sosok yang telah menjadi sebab keberadaanku, menyayangi, mengasihi, mencintai, mendidik dan mengarahkan perjalanan hidupku. Semoga Allah mengasihi keduanya sebagaimana mereka mengasihaniku di waktu kecil.

2. Suami dan anakku tersayang Koko Novrizal dan Muhammad Sakha Arkan Wiratama yang telah memberikan suport dan menanti keberhasilan ku.

3. Adiku tersayang Putri Dwi Maha Rani yang mendoakan kesuksesan ku

4. Keluarga besarku yang terus menasihatiku, mengarahkanku, dan memberikan berbagai masukan serta wejangan bagiku dalam meniti cita-cita.

5. Kepada sahabat tersayang Amelia Nurarifah dan Fera Kurniasari terimakasih telah mendampingi dalam setiap langkah perjuangan kita dalam suka dan duka..

6. Seluruh dosen, ustadz, dan guru-guruku yang sangat saya mulyakan. Ilmu yang telah kalian berikan adalah pelita dalam perjalanan hidupku.

7. Seluruh dewan guru di SDN 01 Tulus Ayu yang telah memberi bantuan memperlancar pengambilan data selama proses penelitian Tugas Akhir Skripsi ini. 
8. Semua sahabat-sahabatku teman seperjuangan PGMI, yang selalu memberikan bantuan, motivasi, semangat yang tiada henti-hentinya hingga ananda bisa berjuang hingga akhir dan yang selalu membuat hari-hariku terasa bahagia.

9. Almamaterku Sekolah Tinggi Keguruan dan Ilmu Pendidikan (STKIP) Nurul Huda Sukaraja yang sangat aku banggakan.

\section{DAFTAR PUSTAKA}

Agustina,Lilik, Rustiyarso, Okiana. 2015. "Pengaruh Motivasi Belajar Terhadap Hasil Belajar Sosiologi Di Sma”. Pontianak : FKIP Untan.

Arikunto, Suharsini. 2014. Prosedur Penelitian Menurut Pendekatan Praktis. Jakarta : Reneka Cipta.

Bagus, I Gusti Darmawan. 2016. Pengaruh Motivasi Belaajar Terhadap Hasil Belajar Siswa Kelas XI Pada Mata Pelajaran Menggambar Bangunan SMA Negeri 1 Seyegan. Yogyakarta : Fakultas Teknik Universitas Negeri Yogyakarta.

Dimyati dan Mudjiono. 2010. Belajar dan Pembelajaran. Jakarta : PT Rineka Cipta.

Djamarah, Syaiful Bahri. 2011. Psikologi Belajar. Jakarta : PT Rineka Cipta.

Dalyono, Muhammad. 2015. Psikologi Pendidikan. Jakarta : Rineka Cipta.

Darmawan, Deni. 2016. Metode Penelitian Kuantitatif. Bandung : Pt Remaja Rosdakarya.

Fathurrohman dkk. 2010. Setrategi Belajar Mengajar. Bandung : Refika Aditama.

Hanifah, Nanang Dan Cucu Suhana. 2010. Konsep Strategi Pembelajaran. Bandung : Refika Aditiya.

Hidayah, Ana. 2013. Pengaruh Motivasi Belajar Terhadap Hasil Belajar Matematika Siswa Kelas VII SMP Negeri 1 Gunung Jati Kebupaten Cirebon. Cirebon : Institut Agama Islam Negeri (IAIN) Syekh Nurjati Cirebon.

Kesumawati, Nila Dan Ichwan Aridanu. 2018. Statistik Parametrik Penelitian Pendidikan. Palembang : NoerFikri Offset.

Martono, Nanang. 2011. Metodologi Penelitian Pendidikan. Jakarta : Rinieka Cipta.

Malik, Oemar. 2010. Proses Belajar Mengajar. Jakarta : PT Bumi Aksara.

Mutamainah, Mut'ah. 2014. Pengaruh Motivasi Belajar Terhadap Hasil Belajar Siswa Pada Bidang Study Sejarah Kebudayaan Islam Di Mts N 19 Jakarta. Jakarta : Fakultas IImu Tarbiyah Dan Keguruan UIN Syarif Hidayatullah.

Nasir, Muhammad. 2013. Metodologi Penelitian. Jakarta : Ghalia Indonesia.

Natanael, Yonatan. 2014. Belajar Otididak SPSS Pasti Bisa. Jakarta : PT Elex Media Kompuffindo.

Purwanto, Ngalim. 2007. Psikologi Pendidikan. Bandung: Remaja Rosdakarya.

Riduwan, Adun Rusyana, dan Enas. 2013. " Cara Mudah Belajar SPSS dan Aplikasi Statistik Penelitian". ALFABETA.

Rusman. 2013. Belajar dan Pembelajaran Berbasis Komputer. Bandung: Alfabeta.

Sardiman. 2016. Interaksi Dan Motivasi Belajar Mengajar. Jakarta : PT Raja Grafindo Persada.

Sudijono, Anas. 2015. Pengantar Statistik Pendidikan. Jakarta, PT Raja Grafindo.

Prima Septiana Anggraeni, Sri Enggar Kencana Dewi 
24 | Jemari: Jurnal Edukasi Madrasah Ibtidaiyah, Vol. 3 No. 1, Halaman: 18 - 24, january, 2021

Sudjana, Nana. 2010. Penilaian Hasil Belajar. Bandung : Sinar Baru Algesindo.

Suprijono, Agus. 2017. Cooperative Learning (teori dan aplikasi PAIKEM). Yogyakarta, Pustaka Pelajar.

Susanto, Ahmad. 2013. Teori Belajar dan Pembelajaran di Sekolah Dasar. Jakarta, Kencana Prenada.

Sofiyan Siregar, Sofyiyan, 2015. Statistik Deskriptif Untuk Penelitian. Jakarta : Raja Grafindo.

Sugiyono, 2013. Metode Penelitian Kuantitatif Kualitatif dan R\&D. Bandung : Alfabeta.

Sugiyono. 2012. Statistik Untuk Penelitian. Bandung, Alfabeta.

Uno, B Hamzah. 2017. Teori Motivasi \& Pengukurannya Analisis Dibidang Pendidikan. Jakarta : PT Bumi Aksara.

Warti, Elis. 2016. Pengaruh Motivasi Belajar Siswa terhadap Hasil Belajar Matematika Siswa di SD Angkasa 10 Halim Perdana Kusuma Jakarta Timur. Jakarta : STKIP Kusuma Negara.

Zuldafrial. 2012. Strategi Belajar Mengajar. Surakarta : Cakrawala Media 